\title{
PENINGKATAN KETRAMPILAN PIJAT OKSITOSIN PADA KADER DI WILAYAH POSYANDU MELATI RT 04 RW 06 KEL. TASIKMADU, KEC. LOWOKWARU, KOTA MALANG
}

\author{
Yuliyanik $^{1}$ \\ STIKES Widyagama Husada, Malang, Jawa Timur, Indonesia \\ 1*Email: yulijuju67@yahoo.com
}

\begin{abstract}
Oxytocin massage also makes mothers more comfortable in breastfeeding babies. Situation analysis obtained from community service partners at Posyandu Melati RT 04 RW 06 KelurahanTasikmadu in Lowokwaru District, Malang City is that posyandu cadres do not know about oxytocin massage and the benefits of oxytocin massage. This is due to a lack of understanding of the importance of oxytocin massage and the lack of knowledge about oxytocin massage. The solution offered by the Community Service implementation team is counseling and practice to cadres about oxytocin massage and has been carried out by the implementing team. The results and outcomes that we got in this activity were the improvement of Posyandu Melati cadre skills RT 04 RW 06 Tasikmadu Kel. Lowokwaru Kec. Malang City about oxytocin massage to help the mother to make her milk smooth, mother also felt comfortable.
\end{abstract}

Keyword : cadre, oxytocin massage, breast milk (ASI)

\section{PENDAHULUAN}

Masa nifas adalah salah satu masa yang perlu perhatian, setelah ibu melahir kan bayinya. Salah satu yang penting dan yang perlu diperhatikan adalah kebutuhan bayi yaitu ASI. Diharapkan ibu dapat memberikan ASI pada bayinya ASI Eksklusif, yaitu memberikan ASI saja sampai usia bayi 6 bulan tanpa diberikan susu tambahan atau makanan tambahan. Salah satu masalah yang sering dihadapi ibu adalah tidak keluarnya ASI dengan lancar. Sehingga ibu merasa kesulitan memberikan ASI, bayi menjadi kurang minum sehingga bayi rewel dan tidur tidak nyenyak. Bayi yang tidurnya kurang dapat berpengaruh pada berat badan yang tidak naik dan ibu juga kurang istirahat. Salah satu yang dapat dilakukan untuk membantu agar ASI keluar dengan lancer adalah dengan pijat oksitosin (Latifah, 2015).

Pijat merupakan sentuhan pada jaringan lunak tubuh seperti otot dengan tangan, lengan atau siku.Pijat merupakan sebuah terapi yang sudah populer di Indonesia. Pijat oksitosin yaitu melakukan pijatan khusus pada punggung ibu menyusui, guna merangsang pengeluaran hormon oksitosin di dalam tubuh. Oksitosin adalah hormon yang bereaksi ketika tubuh manusia mendapat sentuhan. Hormon ini diproduksi oleh salah satu bagian otak yang disebut hipotalamus, kemudian dikeluarkan oleh kelenjar yang berada di bagian belakang otak. Cara kerja hormon oksitosin pada otak mirip seperti efek morfin, yang membuat seseorang merasa bahagia dan mengurangi rasa sakit.

Oksitosin dapat memberi stimulasi saat persalinan dan memberikan stimulasi pada puting untuk proses menyusui, sekaligus berperan pada produksi susu dan hubungan dengan bayi. Ini salah satu alasan kenapa pijat oksitosin dipercaya bisa membantu dalam proses menyusui. Sementara itu, pijat diketahui memiliki manfaat dalam memulihkan keseimbangan hormon pasca persalinan. Hormon dan prolaktin yang bermanfaat untuk proses menyusui meningkat.Manfaat pijat secara umum yaitu 
untuk melancarkan aliran darah, membuat timbulnya perasaan rileks, menurunkan rasa nyeri, dan menurunkan ketegangan pada otot dan saraf. Penelitian oleh para ilmuwan menemukan bahwa memijat mampu mengurangi ketegangan syaraf, menurunkan kadar hormon pemicu stres, membantu mencegah depresi dan menurunkan resiko penyakit kardiovaskular. Manfaat ini diperoleh yang terutama untuk ibu menyusui setelah masa persalinan.

Hasil identifikasi dan analisis situasi pada mitra Pengabdian kepada masyarakat didapatkan beberapa permasalahan, diantaranya kurangnya pengetahuan kader tentang pijat oksitosin, kurangnya keterampilan kader tentang pijat oksitosin, banyaknya ibu nifas yang ASI nya tidak lancar, kurangnya pengetahuan ibu dan manfaat tentang pijat oksitosin dan ibu masih memberikan susu formula pada bayinya.

Solusi yang ditawarkan adalah peningkatan pengetahuan pendidikan kesehatan, meliputi aspek peningkatan pengetahuan tentang pijat oksitosin yang di ikuti oleh kader kesehatan dan ibu dengan penyuluhan dan praktik.

\section{METODE PELAKSANAAN}

Metode pelaksanaan Pengabdian kepada masyarakat dalam upaya Peningkatan Kader Kesehatan tentang Pijat oksitosin adalah sebagai berikut:

1. Penyusunan leaflet tentang pijat oksitosin. Kondisi Posyandu dapat dilihat pada Gambar 1.

2. Sosialisasi dengan Ketua Kader Posyandu Melati RT 04 RW 06 Kel. Tasikmadu Kec. Lowokwaru. Persiapan penyuluhan dapat dilihat pada Gambar 2.

3. Penyusunan dan penandatanganan kesepakatan antara STIKES Widyagama Husada dengan Ketua kader Posyandu Melati RT 04 RW 06 Kel. Tasikmadu Kec. Lowokwaru untuk melaksanakan pijat oksitosin.

4. Penyuluhan pijat oksitosin kepada kader Posyandu Melati RT 04 RW 06 Kel. Tasikmadu Kec. Lowokwaru

5. Pelatihan kepada kader Posyandu Melati RT 04 RW 06 Kel. Tasikmadu Kec. Lowokwaru tentang pijat oksitosin

6. Evaluasi terhadap peserta penyuluhan Supervisi dan Pelaporan Pelaksanaan Program

7. Terminasi dan Penyusunan Rencana Tindak Lanjut

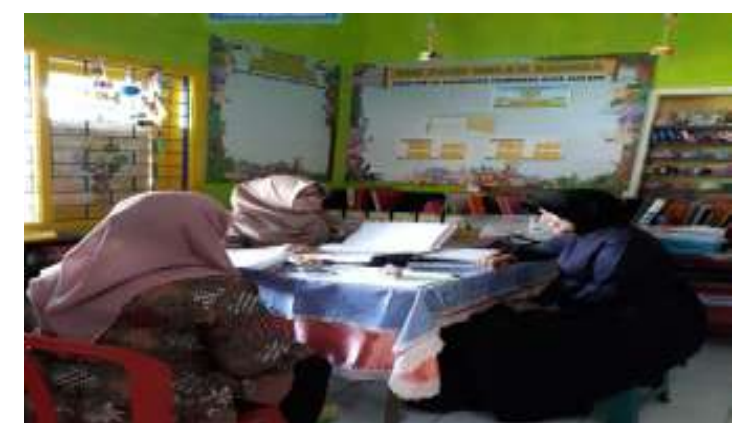

\section{Gambar 1. Kondisi dengan Ketua Kader Posyandu} (Sumber: doc. Pribadi, 2018

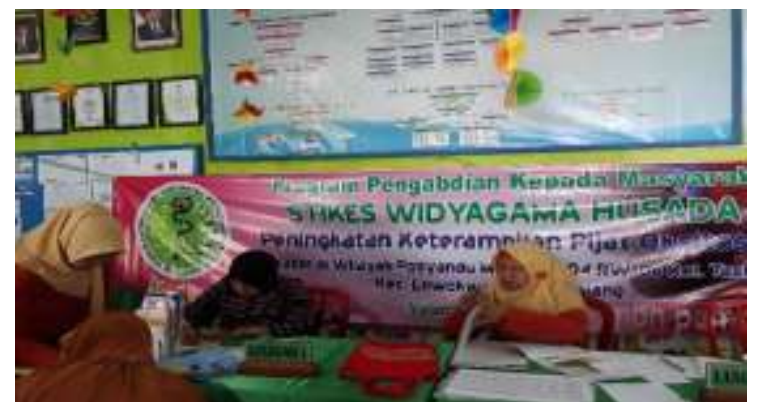

Gambar 2. Persiapan Penyuluhan (Sumber: doc. Pribadi, 2018) 


\section{HASIL DAN PEMBAHASAN}

\section{A. Hasil Pengabdian Kepada Masyarakat}

Kader sangat antusias dan kooperatif sekali selama proses pelaksanaan Pengabdian kepada Masyarakat. Hasil dari penyuluhan dan praktik pijat oksitosin yang telah dilaksanakan sangat bermanfaat bagi para kader. Kader merasakan manfaat dari penyuluhan dan praktik yang telah diberikan. Sebelum diberikan penyuluhan, para kader belum pernah mendengar dan belum memahami tentang pijat oksitosin. Setelah dilakukan penyuluhan dan praktik pijat oksitosin, Kader mendapat pengetahuan dan ketrampilan yang baru tentang pijat oksitosin.

Kader yang terlibat sebanyak 20 orang kader, hanya 1 orang yang pernah mendengar dan membaca tentang pijat oksitosin di media massa, tetapi kurang memahami praktiknya. Evaluasi dari penyuluhan dan praktik tentang pijat oksitosin yang dilaksanakan1(satu) bulan setelah kegiatan didapatkan bahwa para kader sudah dapat menerapkan pijat oksitosin kepada ibu nifas yang mengalami keluhan ASI kurang lancar. Penyuluhan kepada kader dapat dilihat pada Gambar 3. Praktik pijat oksitosin sesi I dapat dilhat pada Gambar 4.

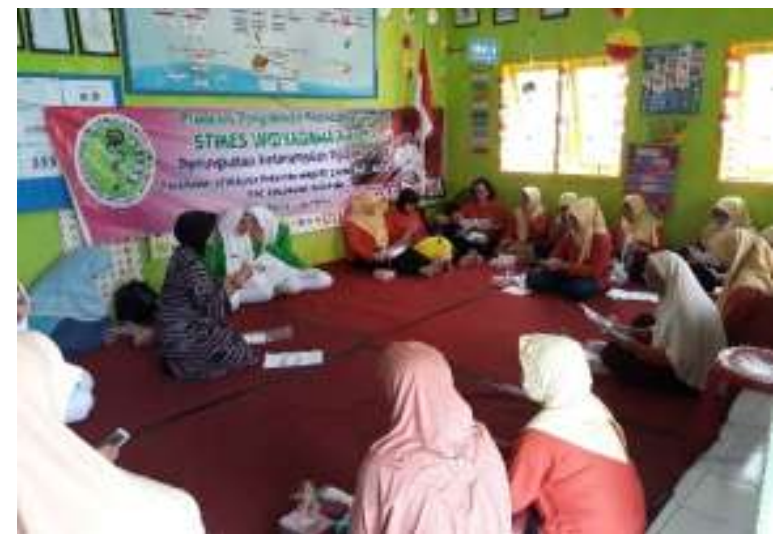

Gambar 3. Penyuluhan Kepada Kader (Sumber: doc. Pribadi, 2018)

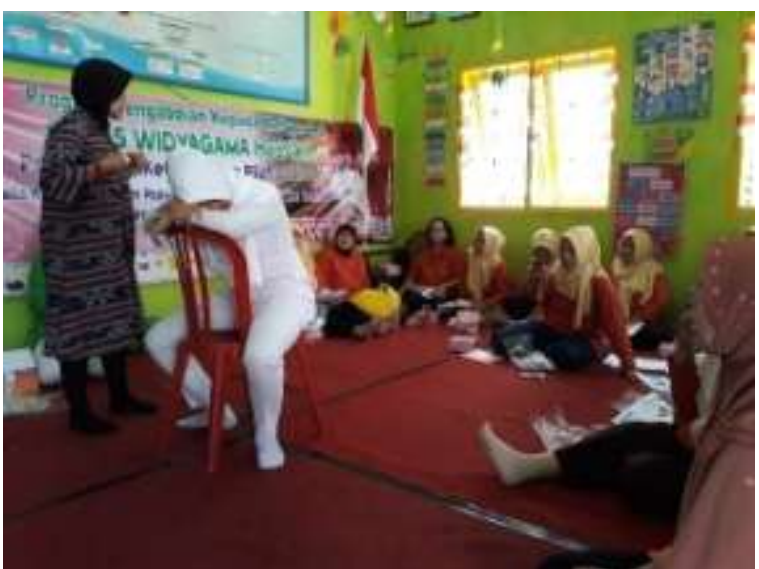

Gambar 4. Praktik Pijat Oksitosin Sesi I (Sumber: doc. Pribadi, 2018)

\section{B. Pembahasan}

ASI merupakan kebutuhan utama bagi bayi. ASI juga sangat bermanfaat bagi ibu dan bayi. Bagi bayi, ASI merupakan pertahanan yang bagus bagi imunitas atau kekebalan daya tahan tubuh bayi. Bagiibu, memberikan ASI bermanfaat dalam membantu proses involusi atau kembalinya rahim ibu kebentuk semula serta menambah kontak kasih saying antar ibu dan bayi. Oleh karena itu bagi ibu nifas yang mengalami ASInya kurang lancer dapat berpengaruh bagi ibu dan bayinya. Salah satu upaya untuk membantu keluarnya ASI adalah dengan dilakukannya pijat oksitosin. 
Praktik pijat oksitosin sesi II dapat dilihat pada Gambar 5. Diskusi dengan para kader dapat dilihat pada Gambar 6. Keaktifan kader dapat dilhat pada Gambar 7.

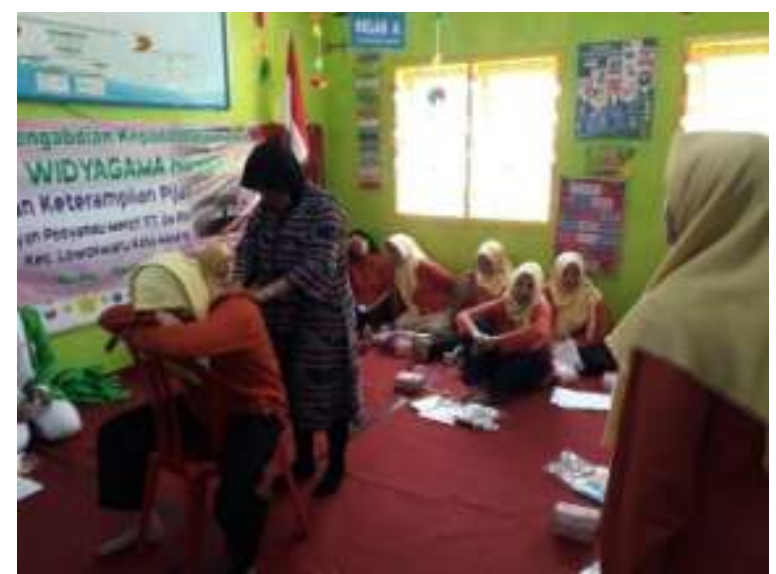

Gambar 5. Praktik Pijat Oksitosin Sesi II (Sumber: doc. Pribadi, 2018)

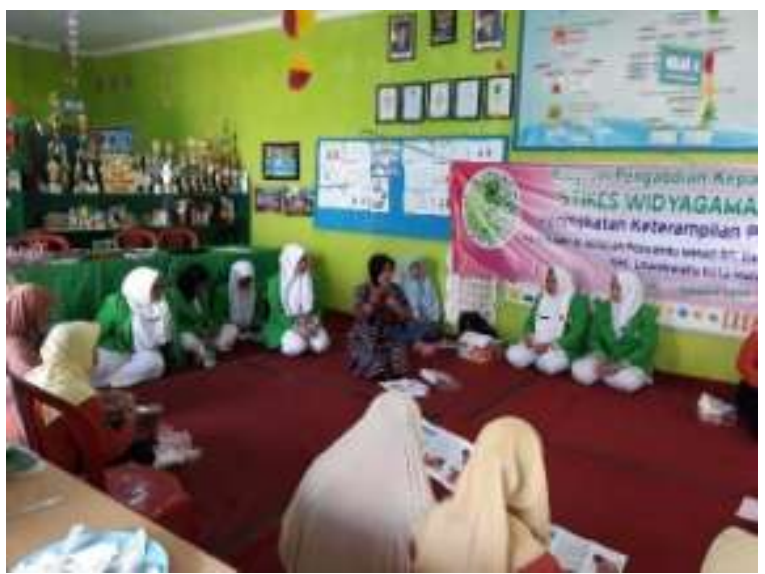

Gambar 6. Diskusi dengan Para Kader (Sumber: doc. Pribadi, 2018)

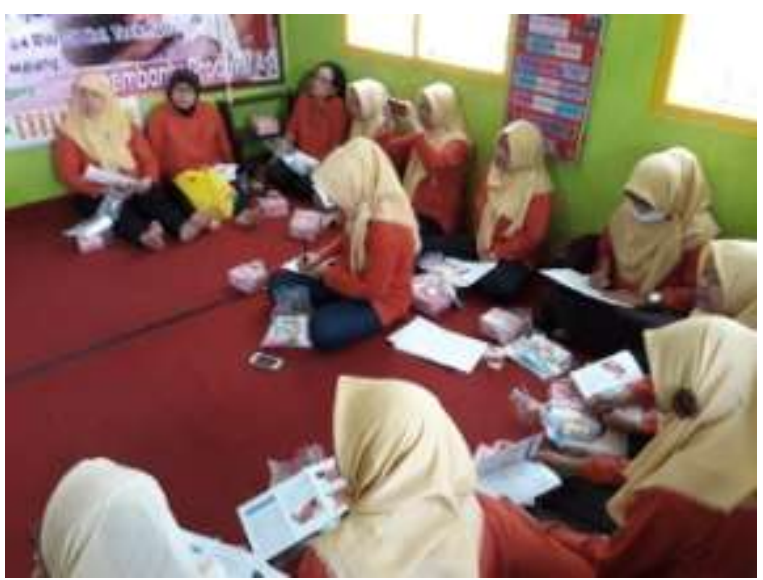

Gambar 7. Kader Aktif Berdiskusi (Sumber: doc. Pribadi, 2018)

Upaya tersebut dapat dilakukan oleh para kader di posyandu dalam membantu ibu agar ASInya dapat keluar dengan lancar. Peningkatan ketrampilan pijat oksitosin ini dilakukan dengan memberikan penyuluhan dan praktik tentang pijat oksitosin kepada para kader. Meningkatnya pengetahuan dan ketrampilan pijat oksitosin pada para kader diharapkan dapat membantu para ibu nifas yang mengalami keluhan dengan ASInya. 


\section{KESIMPULAN}

Kesimpulan dari Pengabdian kepada Masyarakat tentang pijat oksitosin yang telah dilaksanakan sangat bermanfaat bagi para kader. Para kader mendapat peningkatan pengetahuan dan praktik tentang pijat oksitosin. Para kader dapat memahami penyuluhan dan praktik pijat oksitosin yang telah diberikan, para kader sangat antusias selama mengikuti penyuluhan dan praktik yang diberikan. Para kader banyak bertanya tentang pijat oksitosin dan dapat mempraktekkan pijat oksitosin yang telah diajarkan.

\section{REFERENSI}

Endah, SN., Masdinarsah, I. 2011. Pengaruh Pijat Oksitosin Terhadap Pengeluaran Kolostrum Pada Ibu Post Partum Di Ruang Kebidanan Rumah Sakit Muhammadiyah Bandung Tahun 2011. Jurnal Kesehatan Kartika

Latifah, J., Wahid, A., Agianto. 2015. Perbandingan Breast Care Dan Pijat Oksitosin Terhadap Produksi Asi Pada Ibu Post Partum Normal. DK Vol.3/No.1/Maret.

Machmudah, Khayati, N. 2014. Produksi ASI Ibu Post Seksio Sesarea Dengan Pijat Oketani Dan Oksitosin.Jurnal Ners Vol. 9 No. 1 April 2014: 104-110.

Rofi'ah, S., Widatiningsih, S., Rahayuni, C. 2016. Pengaruh Pijat Oksitosin Dan Mobilisasi Dini Terhadap Pengeluaran Kolostrum Ibu Post Sectio Caesarea. RAKERNAS AIPKEMA 2016 "Temu Ilmiah Hasil Penelitian dan Pengabdian Masyarakat".

Suryani, E., Astuti, EW. 2013. Pengaruh Pijat Oksitosin Terhadap Produksi Asi Ibu Postpartum Di BPM Wilayah Kabupaten Klaten. Jurnal Terpadu Ilmu Kesehatan, Volume 2, Nomor 2, Nopember 2013, hlm.41-155.

Wulandari, FT., Aminin, F., Dewi, U. 2014. Pengaruh Pijat Oksitosin Terhadap Pengeluaran Kolostrum Pada Ibu Post Partum Di Rumah Sakit Umum Daerah
Provinsi Kepulauan Riau. Jurnal Kesehatan, Volume V, Nomor 2,Oktober. 